\title{
SIMULATION AND EXPERIMENTAL STUDY OF SCR INJECTION SYSTEM
}

\author{
Jun Du, Prof. \\ Yan Zhang, Postgraduate \\ Zeliang Cai, Postgraduate \\ College of Energy and Power, Jiangsu University of Science and Technology, Jingkou, Zhenjiang, China
}

\begin{abstract}
According to actual engineering test, we design a linear controlled spray ammonia grille, and apply it to the SCR injection system of ship tail gas treatment. In this paper, the geometric model of ammonia injection grid was built in the flue of diesel engine, and the effects of spray atomization, ammonia uniformity and urea droplet distribution on spray atomization were simulated. Then the test bench was set up to observe the injection status of the ammonia injection grille. The $\mathrm{NO}_{x}$ content of the outlet was measured by the original data of the flue gas, and the experimental data were processed. We calculate the denitrification rate by taking the average value to verify the correctness of the spray ammonia grid scheme.
\end{abstract}

Keywords: Ammonia grille; Flow field; Uniformity; SCR test; The denitrification rate

\section{INTRODUCTION}

In order to achieve a good catalytic effect, the SCR reactor needs to control the change of parameters of the front-end of the catalytic converter. The reactor gas mixing state and system denitrification rate and reducing agent distribution uniformity is important link of ammonia, the distribution uniformity of $\mathrm{NH}_{3}$ depends on the atomization quality of urea. This would require the SCR injection system for structural optimization, by using the high quality of urea [1], control suitable injection amount, good atomization effect, reasonable structure design and so on methods to improve the spray atomization effect, the effect of jet atomization in order to improve the removal rate of $\mathrm{NO}_{\mathrm{x}}$.

At present, the SCR system has a key research object besides the catalyst study, which is the injection system, there are many people working on the simulation of ammonia grille and its corresponding bench experiment [2]. Many SCR denitrification experiments use air to replace the exhaust gas produced by diesel engines $[3,4]$ replacing $\mathrm{NH}_{3}$ with carbon oxide, explore the mixing uniformity of waste gas and $\mathrm{NH}_{3}$, and the distribution of flow field, concentration field and pressure field in the flue, and obtain the optimal design scheme of the injection device in the
SCR catalytic reaction system $[5,6,7]$. Subhasish Bhattachaijee used Fluent to simulate the fluidity of air flow within the SCR catalytic reactor and its effect on the concentration distribution of $\mathrm{NH}_{3}$ in the first layer catalyst [8]. The result is that the larger the flow resistance in the catalytic converter, the better the uniformity of $\mathrm{NH}_{3}$. Adams B established the CFD model and simulated $\mathrm{NH}_{3}$ injection [9], the results show that the injection speed of $\mathrm{NH}_{3}$ can be adjusted in a certain range, and the concentration distribution of $\mathrm{NH}_{3}$ at the entrance of the catalyst is more uniform. Naqvi simulated the effect of spraying ammonia grille on velocity uniformity in the flue of SCR system [10]. Enrico Tronconi simulated the distribution of ammonia injection and concentration field in the SCR injection system by simulation software, and proposed the optimal design scheme [11]. Tao Qiu used the energy conservation equation and SCR reaction model, proposing a method for estimating the downstream exhaust temperature of the catalyst [12]. Ossi Tapani Kaario established a single droplet simulation phase diagram, which predicted the optimal operation area of the SCR system and verified the HLR method at high Reynolds number [13].

In this paper, $\mathrm{NO}_{\mathrm{x}}$ is used to determine the amount of $\mathrm{NO}_{\mathrm{x}}$ in flue gas under stable condition of diesel engine by $\mathrm{NO}_{\mathrm{x}}$ 
sensor to calculate the amount of urea solution that needs to be sprayed. Then, a suitable geometrical model for the injection of ammonia grille was established to simulate the effect of spray atomization flow field distribution, ammonia uniformity and urea droplet distribution on the result of spray atomization. And the test bench was built to observe the injection status of the injection grate and calculate the denitrification rate to verify the correctness of the injection.

\section{THE BASIC MODEL}

At present, there are three main types of Ammonia-Injection Grid used in industry: vortex static mixing type, linear control type and zoned control type. According to the actual engineering test, this paper designs a linear control type of injection grate, which is arranged in the flue, the axial jet, 4 rows $\times 6$ holes, and the aperture is $1.06 \mathrm{~mm}$. The layout of the injection of ammonia grille in the flue is shown in Fig. 1.

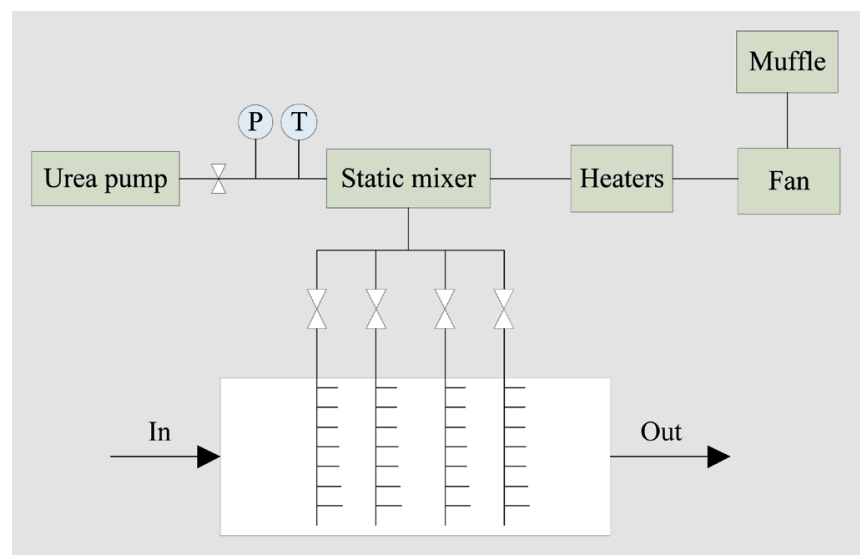

Fig. 1. Spray ammonia grid piping layout

\section{THE TAB MODEL}

The TAB model is a common model for simulating droplet collision and crushing in FLUENT simulation system, and also called Taylor ratio model [14]. This kind of model is suitable for low speed spray, due to fluid flow and collision between the droplet surface wave droplets produced force in the process of collision, and amplitude increases, this is a major cause of droplet breakage. The force equation of the droplet surface in TAB model is as follows:

$$
\begin{gathered}
F_{a}-F_{\mu}-F_{\sigma}=\frac{d^{2} y}{d t^{2}} \\
F_{a}=\frac{C_{F} \rho_{a}}{C_{b} \rho_{d} \gamma^{2}}\left|\mu_{a}-\mu_{d}\right|^{2} \\
F_{\mu}=C_{d} \frac{\mu_{d}}{\rho_{d} \gamma^{2}} \frac{d y}{d t} \\
F_{\sigma}=C_{k} \frac{\sigma y}{\rho_{d} \gamma^{3}}
\end{gathered}
$$

In Eq. (1), (2), (3) and (4):

$\mathrm{Fa}$ - the aerodynamic force on the droplet surface of the atomizing liquid $\mathrm{N} / \mathrm{m}$ :

$F_{\sigma}-$ surface tension on the surface of a droplet, N/m:

$F_{\mu}$ - the viscous force on the surface of a droplet, N/m:

$\mathrm{r} \quad$ - the initial droplet radius, $\mathrm{m}$;

$\mu_{\mathrm{d}}-$ the kinetic viscosity of liquid drop, $\mathrm{kg} /(\mathrm{m} \cdot \mathrm{s})$;

$C_{F}, C_{\mathrm{k}}, C_{\mathrm{d}}$ - dimensionless parameters.

\section{DISCRETE PHASE MODEL}

The urea solution is injected into the flue, and atomized into fine droplets, but its content is the exhaust flow accounted for less, so the use of spray process is described DPM discrete model, have occurred due to heat transfer and evaporation of liquid droplets and gas mixing phenomenon in the process of heat and mass transfer effects, hence there is a need to consider the droplet discrete and continuous gas phase between. Firstly, in the absence of discrete phase on the basis of the continuous phase to continuous phase after the simulation calculation results as the initial conditions, the activation of discrete items, for each source of jet flow field simulation calculation.

\section{THE CHEMICAL REACTION MECHANISM OF UREA DECOMPOSITION}

The pyrolysis reaction and hydrolysis of isocyanate will occur in the flue, and Yim et al. studied the reaction rate of urea decomposition and the experimental verification. Therefore, this paper USES the law to simulate the pyrolysis and hydrolysis rate of urea [15]. The equations are as follows:

$$
\begin{gathered}
r_{1}=A_{1} \exp \left(\frac{-E_{1}}{R T}\right) C\left(\mathrm{NH}_{2}\right)_{2} \mathrm{CO} \\
r_{2}=A_{2} \exp \left(\frac{-E_{2}}{R T}\right) C_{H N C O} \cdot C_{H_{2} O}
\end{gathered}
$$

In Eq. (5) and (6):

$\mathrm{r}_{1}$ - the reaction rate of urea pyrolysis;

$\mathrm{r}_{2}$ - the reaction rate of urea hydrolysis;

$A_{1}, E_{1}, A_{2}, E_{2}-$ the reaction rate constant;

$\mathrm{A}_{1}=4900 \mathrm{~m}^{3} \cdot \mathrm{kmol}^{-1} \cdot \mathrm{s}^{-1}$;

$\mathrm{E}_{1}=2.3033 \times 10^{7} \mathrm{~J} \cdot \mathrm{kmol}^{-1}$;

$\mathrm{A}_{2}=2.5 \times 10^{8} \mathrm{~m}^{6} \cdot \mathrm{kmol}^{-2} \cdot \mathrm{s}^{-1}$;

$\mathrm{E}_{2}=6.222 \times 10^{7} \mathrm{~J} \cdot \mathrm{kmol}^{-1}$.

\section{DESIGN OF PARAMETER}

\section{DETERMINATION OF UREA DEMAND}

This paper takes a type of Marine diesel engine as an example, measured the volume flow of flue gas under stable condition of diesel engine was $V=49211 \mathrm{~m}^{3} / \mathrm{h}$ and the concentration of the $\mathrm{NO}_{\mathrm{x}}$ was $\rho=600 \mathrm{ppm}$, and calculated the amount of urea solution to be sprayed from this. 
It is assumed that the mole ratio of $\mathrm{NO}_{2}$ to $\mathrm{NO}$ in the exhaust gas of a marine diesel is $1 / 9$, and the Molar mass are $\mathrm{M}_{\mathrm{NO}}=30 \mathrm{~g} / \mathrm{mol} ; \mathrm{M}_{\mathrm{NO} 2}=46 \mathrm{~g} / \mathrm{mol}$, then the calculation formula of the $\mathrm{NO}_{\mathrm{x}}$ 's average Molar mass is:

$$
\bar{M}=0.1 \times M_{\mathrm{NO}_{2}}+0.9 \times M_{\mathrm{NO}}=31.6 \mathrm{~g} / \mathrm{mol}
$$

In this formula,

$\mathrm{M}_{\mathrm{NO}}$ - the Molar mass of $\mathrm{NO}$, value as $30 \mathrm{~g} / \mathrm{mol}$;

$\mathrm{M}_{\mathrm{NO} 2}$ - the Molar mass of $\mathrm{NO}_{2}$, value as $46 \mathrm{~g} / \mathrm{mol}$.

Therefore, the mass of $\mathrm{NO}_{\mathrm{x}}$ in unit time is:

$m=\rho \times \frac{\bar{M}}{\overline{M_{V}}} \times V=600 \times \frac{31.6}{22.4} \times 49211=41.65 \times 10^{6} \mathrm{mg}=41.65 \mathrm{~kg}$

In this formula, $\overline{M_{V}}-$ the average molar volume of $\mathrm{NO}_{\mathrm{x}}$; under standard conditionsthe molar volume of gas is $22.4 \mathrm{~L} / \mathrm{mol}$.

The relationship between the four reactants $\mathrm{CO}\left(\mathrm{NH}_{2}\right)_{2}, \mathrm{NH}_{3}$, $\mathrm{NO}$ and $\mathrm{NO}_{2}$ is as follow.

Rapid reaction:

$$
\begin{array}{ccc}
\mathrm{CO}\left(\mathrm{NH}_{2}\right)_{2}-2 \mathrm{NH}_{3} & \mathrm{NO}-\mathrm{NO}_{2} \\
1 & 1 & 1 \\
\mathrm{n}_{1} & \mathrm{n}_{2} & 0.1 \mathrm{n}
\end{array}
$$

Standard reaction:

$$
\begin{array}{cc}
\mathrm{CO}\left(\mathrm{NH}_{2}\right)_{2}-2 \mathrm{NH}_{3}-2 \mathrm{NO} \\
1 & 2 \\
\mathrm{n}_{3} & 0.9 \mathrm{n}-\mathrm{n}_{2}
\end{array}
$$

In this formula: $\mathrm{n}$ - the amount of substance of $\mathrm{NO}_{\mathrm{x}}$ in exhaust gas; $\mathrm{n}_{1}$ - the amount of urea material substance required for $\mathrm{NO}_{\mathrm{x}}$ 's rapid reaction; $\mathrm{n}_{2}$ - the amount of $\mathrm{NO}$ substance involved in rapid reactions; $\mathrm{n}_{3}$ - the amount of urea material substance required for $\mathrm{NO}_{\mathrm{x}}$ 's standard reaction.

It can be obtained by the proportional formula: $n_{1}=0.1 n$; $\mathrm{n}_{2}=0.1 \mathrm{n} ; \mathrm{n}_{3}=0.4 \mathrm{n}$.

The SCR injection system is responsible for mixing urea solutions with exhaust emissions from the main engine after the urea solution is injected into the flue pipe by a jet pump. Generally, the power of a diesel engine is greater in a ship's sailing work, the internal temperature of the engine room is high, and the SCR system space is limited, therefore, the urea solution with mass concentration of $40 \%$ and density of $1.1 \mathrm{~kg} / \mathrm{m}^{3}$ is chosen as SCR denitrification reducer in this paper, its freezing point is 0 degrees centigrade, so it can be stored in the ship's cabin for a long time. And it avoids occurrence of ice during the flight, affecting the jet effect.

Therefore, the amount of urea required to spray per unit of time:

$m_{\text {urea }}=\left(\mathrm{n}_{1}+n_{3}\right) \times 60 \div 40 \%=0.5 \times \frac{41.65}{31.6} \times 60 \div 40 \%=98.85 \mathrm{~kg} / \mathrm{h}$

\section{BASIC ASSUMPTIONS}

In order to achieve the atomization effect of SCR injection system and easy to operate, this chapter makes the following assumptions about the simulation process:

(1) Exhaust gas from the diesel engine is considered an ideal gas;

(2) Because the import and export temperature of the SCR system is small, and the thermal loss of the gas in the whole process is not considered, the whole simulation process is set up as an adiabatic system;

(3) Assuming that the flue gas flow in the catalyst channel is constant and incompressible flow;

(4) Set the wall of the flue as viscous flow, no slip and no heat conduction on the wall surface.

\section{BOUNDARY CONDITION SETTING}

The numerical simulation of flue gas mixing with $\mathrm{NH}_{3}$ is divided into two velocity inlets and one pressure outlet condition:

Tab. 1. Inlet flue gas parameter setting

\begin{tabular}{|c|c|c|c|c|c|c|c|}
\hline $\begin{array}{c}\text { NO } \\
\text { concen- } \\
\text { tration } \\
\text { in inlet } \\
\text { flue gas }\end{array}$ & $\begin{array}{c}\text { Velocity } \\
\text { of flow } \\
\text { ppm }\end{array}$ & $\begin{array}{c}\text { Tem- } \\
\text { perature }\end{array}$ & \multicolumn{5}{|c|}{$\begin{array}{c}\text { The mole fraction } \\
\text { of each component (\%) }\end{array}$} \\
\hline 600 & 14.8 & 623 & 0.001 & 0.036 & 0.097 & 0.148 & 0.718 \\
\hline
\end{tabular}

Relevant studies show that the mixing rate is well when the urea injection rate is equal to the exhaust gas exhaust rate [16], $\mathrm{V}_{\text {injection }}=\mathrm{V}=14.8 \mathrm{~m} / \mathrm{s}$.

Tab. 2. Setting of reducing agent inlet parameters

\begin{tabular}{|c|c|c|c|c|c|c|}
\hline $\begin{array}{c}\text { Velocity } \\
\text { of flow }\end{array}$ & $\begin{array}{c}\text { Tem- } \\
\text { perature }\end{array}$ & $\begin{array}{c}\text { Tur- } \\
\text { bulent } \\
\text { intensity }\end{array}$ & $\begin{array}{c}\text { Hydraulic } \\
\text { diameter }\end{array}$ & \multicolumn{3}{|c|}{$\begin{array}{c}\text { The mole fraction } \\
\text { of each component (\%) }\end{array}$} \\
\hline $\mathrm{m} / \mathrm{s}$ & $\mathrm{K}$ & $\%$ & $\mathrm{~mm}$ & $\mathrm{NH}_{3}$ & $\mathrm{O}_{2}$ & $\mathrm{~N}_{2}$ \\
\hline 14.8 & 300 & 10 & 0.5 & 0.05 & 0.2 & 0.75 \\
\hline
\end{tabular}

The export boundary conditions are pressure outlet, wall insulation, viscous flow, no slip, and no heat conduction.

\section{THE SIMULATION ANALYSIS}

\section{OF THE INJECTION OF AMMONIA GRILLE}

The flow field distribution of the flue and the first layer of SCR catalysts entrance section is presented in Fig. 2.
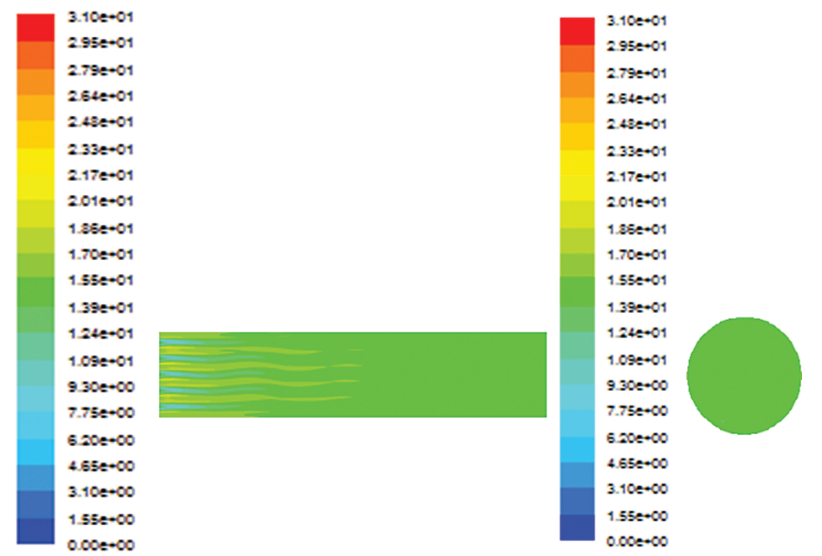

Fig. 2. Flow field Profile 
The internal flow diagram after joined the spraying ammonia grille is presented in Fig. 2. The maximum velocity of export is $18.7 \mathrm{~m} / \mathrm{s}$, due to the size of the ammonia injection grid compared to the size of the whole flue is much smaller, so when the flue gas flows through the ammonia injection grid, the ammonia injection grid has little effect on flow field and the resistance loss is small, There isn't form vortex area and velocity deviation in flue area. Obviously, the influence of spraying ammonia grille flow field is smaller.

The concentration distribution of $\mathrm{NH}_{3}$ in flue is presented in Fig. 3.
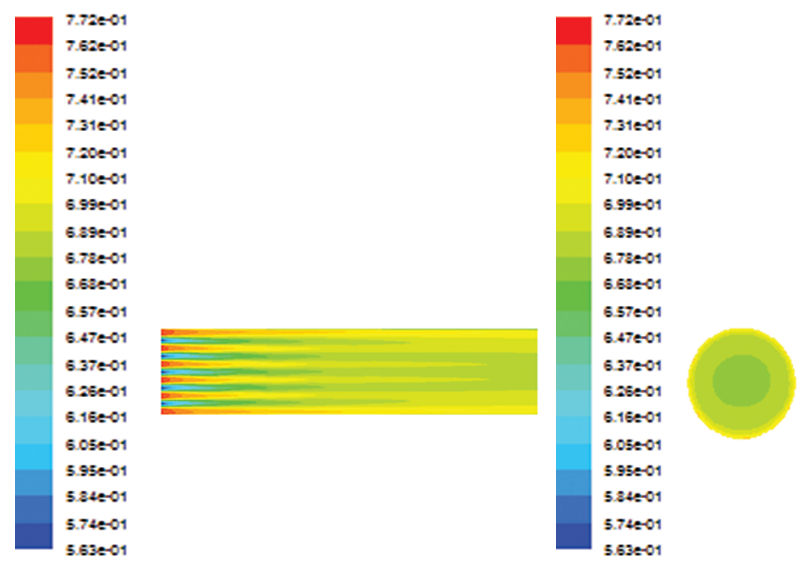

Fig. 3. $\mathrm{NH}_{3}$ concentration profile

The concentration distribution of spraying ammonia grille $\mathrm{NH}_{3}$ is presented in Fig. 3. We can found that the flue near the wall of ammonia concentration is higher than that of the middle section, there is a certain deviation. Uneven distribution of ammonia concentration said that the reductant and the flue gas has failed to fully mix, it is easy to affect denitrification efficiency of the system. Accordingly, decorate spraying ammonia grille can increase the disturbance of flue, improve the ammonia concentration distribution, and improve the denitrification efficiency. After ammonia by multiple nozzle, mainly concentrated in the vent and spread slowly .From the full degree and the uniformity, the type of ammonia injection method is much better and the use of the pipeline space is full. The urea droplet density distribution in the flue is shown in Fig. 4.

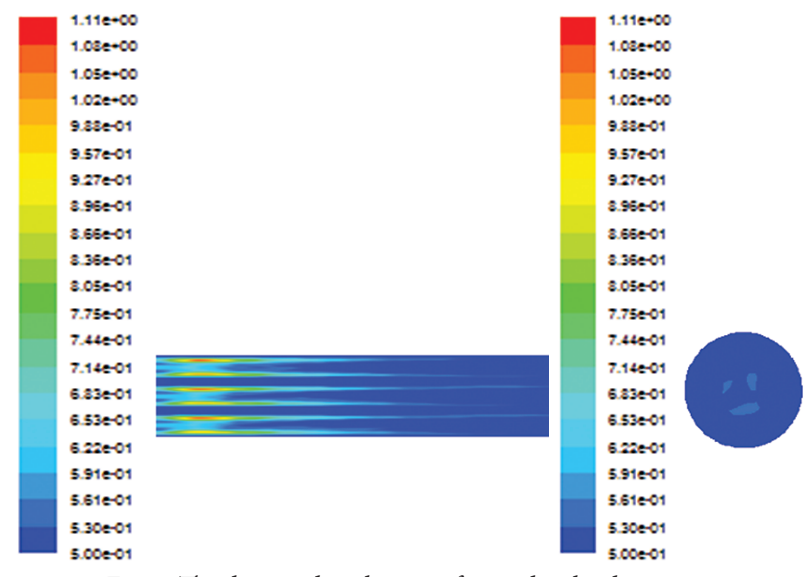

Fig. 4. The density distribution of urea droplet density
The urea droplet distribution of concentration field in the flue after join the ammonia injection grid is presented in Fig. 4. When more than one axis of the nozzle spray, the spray range is wide, the urea solution atomization effect is good and the droplets uniformity is good. The droplet content is higher near the export, by the time the speed is slowly. At the entrance of the first layer of the catalyst residual, only a small amount of urea ,the urea aqueous solution evaporates pyrolysis effect is very good, reductant spray are uniformly mixed with the flue gas and can effectively improve the rate of catalytic reduction reaction.

Based on the analysis above, the ammonia injection grid, $\mathrm{NH}_{3}$ concentration distribution and flow field distribution uniformity droplets in both injection effect is better than a single nozzle, the efficiency of urea pyrolysis generating $\mathrm{NH}_{3}$ is higher, gas mixed more evenly before entering the SCR catalyst layer, it will improve the $\mathrm{NO}_{\mathrm{x}}$ 's conversion rate and reduce the reductant's leak of $\mathrm{NH}_{3}$.

\section{EXPERIMENTAL STUDY}

\section{SCHEME DESIGN}

According to the design of the ammonia injection grid injection effect is good, we will be the device installed in the flue, combination of urea pump, SCR catalytic reactor, control and detection system, such as a test bench, the flow chart is shown in Fig. 5.

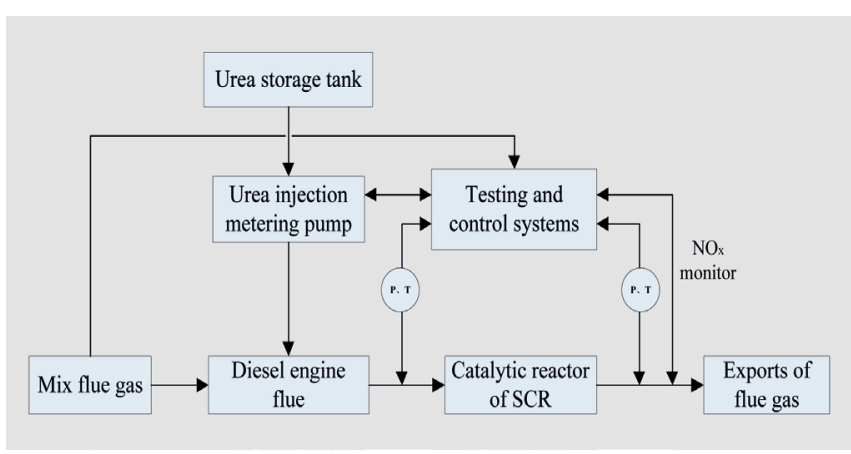

Fig. 5. Experimental flowchart

The equipment includes $\mathrm{NO}_{\mathrm{x}}$ sensor, temperature controller, pressure sensor, gas mixing heater, etc. Before starting the experiment, the injection of the sprayed ammonia grille designed by this paper is conducted to observe the injection status. After that, the measuring instruments used in all experiments are calibrated separately, and the flow control apparatus, thermocouple and sensors are tested to ensure the correctness of the experimental results. Connect all the experimental devices to the test system for normal operation. Turn on the computer, connect the test system with the computer test software, and initialize the test instrument. Adjust the gas flow after entering the equilibrium gas $\mathrm{N}_{2}$. The sealing of the test system is checked to ensure that the connection between each device and the flue is well sealed. Open the electric heater, the gas mixer and SCR reactor were heated to the experimental 
temperature, to reach the set value of flue gas temperature, open the steel cylinder control valve, access the supplied mixed gas, the gas flow balance after a period of time, start the experiment. The details of the experimental scheme are as follows:

Tab. 2. Setting of reducing agent inlet parameters

\begin{tabular}{|c|c|c|c|c|}
\hline $\begin{array}{c}\text { Test } \\
\text { plan }\end{array}$ & $\begin{array}{c}\text { Gas } \\
\text { flow(kg/h) }\end{array}$ & $\begin{array}{c}\mathrm{NO}_{\mathrm{x}} \\
\text { content } \\
(\mathrm{ppm})\end{array}$ & $\begin{array}{c}\text { Exhaust } \\
\text { temperature } \\
(\mathrm{k})\end{array}$ & $\begin{array}{c}\text { Flow } \\
\text { velocity } \\
(\mathrm{m} / \mathrm{s})\end{array}$ \\
\hline $\mathrm{A}$ & 43490 & 473 & 537 & 13.92 \\
\hline B & 61570 & 541 & 592 & 14.1 \\
\hline C & 80214 & 600 & 623 & 14.8 \\
\hline $\mathrm{D}$ & 102733 & 849 & 704 & 15.76 \\
\hline
\end{tabular}

\section{INJECTION TEST OF SPRAY AMMONIA GRILLE}

Before the experiment, the performance of the ammonia jet grille designed in this paper was tested, the injection of urea water solution is shown in Fig. 6.

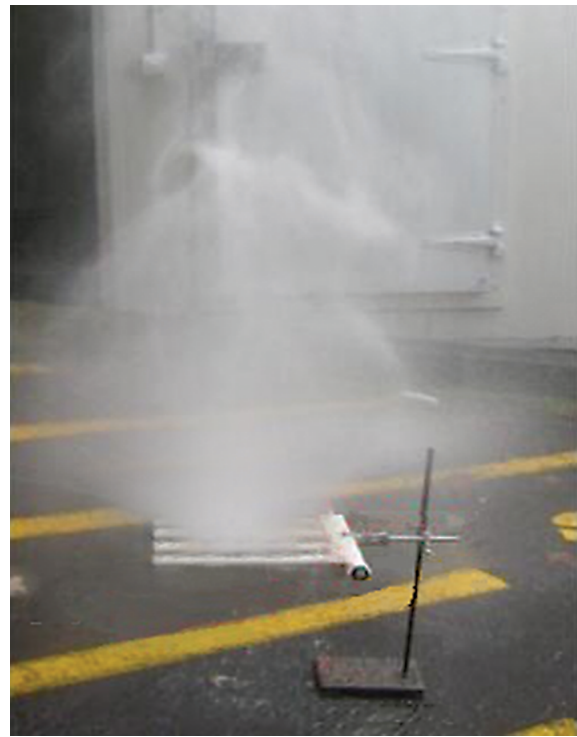

Fig. 6. Injection test diagram of injection of ammonia grille

It can be seen from Fig. 6., the spraying of ammonia grille is better, the liquid squirts out and becomes a tiny droplet of mist, spray mist like to stretch around the center axis, irregular cone, the edges of the droplets are content is significantly lower than the center position, the lower the content of the closer it gets to the surrounding area. But the spray uniformity is good, the injection Angle is large, meet the experiment requirement.

\section{SCR EXPERIMENT DENITRIFICATION RATE}

The urea injection metering pump was started based on the previous urea injection, open the control valve and conduct five experiments for each program, record the $\mathrm{NO}_{\mathrm{x}}$ content of the five flue gas outlet, and find the average value, the experimental data is shown in the Table 4.
Tab. 2. Setting of reducing agent inlet parameters

\begin{tabular}{|c|c|c|c|c|}
\hline $\begin{array}{l}\text { Test } \\
\text { plan }\end{array}$ & $\begin{array}{c}\text { Urea } \\
\text { discharge } \\
(\mathrm{kg} / \mathrm{h})\end{array}$ & jet velocity & $\begin{array}{l}\text { Export } \mathrm{NO}_{\mathrm{x}} \\
\text { content } \\
(\mathrm{ppm})\end{array}$ & $\begin{array}{c}\text { Export } \mathrm{NO}_{\mathrm{x}} \\
\text { content } \\
\text { average } \\
\text { (ppm) }\end{array}$ \\
\hline \multirow{5}{*}{ A } & \multirow{5}{*}{42.25} & \multirow{5}{*}{13.92} & 21.88 & \multirow{5}{*}{28.75} \\
\hline & & & 29.09 & \\
\hline & & & 34.75 & \\
\hline & & & 26.40 & \\
\hline & & & 31.63 & \\
\hline \multirow{5}{*}{ B } & \multirow{5}{*}{68.43} & \multirow{5}{*}{14.1} & 50.21 & \multirow{5}{*}{49.62} \\
\hline & & & 36.65 & \\
\hline & & & 41.00 & \\
\hline & & & 57.19 & \\
\hline & & & 63.05 & \\
\hline \multirow{5}{*}{$\mathrm{C}$} & \multirow{5}{*}{98.85} & \multirow{5}{*}{14.8} & 57.66 & \multirow{5}{*}{53.18} \\
\hline & & & 63.05 & \\
\hline & & & 41.83 & \\
\hline & & & 51.16 & \\
\hline & & & 52.20 & \\
\hline \multirow{5}{*}{$\mathrm{D}$} & \multirow{5}{*}{179.17} & \multirow{5}{*}{15.76} & 107.33 & \multirow{5}{*}{131.79} \\
\hline & & & 142.80 & \\
\hline & & & 155.04 & \\
\hline & & & 132.10 & \\
\hline & & & 121.68 & \\
\hline
\end{tabular}

According to the experimental data in Table 5 and Table 6, the rate of denitrification of each scheme is calculated according to the formula of catalytic reaction rate of SCR system (bottom 7). The results are shown in Fig. 7.

$$
\eta_{\mathrm{NO}}=\frac{\mathrm{NO}_{\text {in }}-\mathrm{NO}_{\text {out }}}{\mathrm{NO}_{\text {in }}} \times 100 \%
$$

In Eq. (7):

NOin - the concentration of NO at the inlet of SCR reactor, $\mathrm{mg} / \mathrm{m} 3$;

NOout - the concentration of $\mathrm{NO}$ at the exit of the SCR reactor, $\mathrm{mg} / \mathrm{m} 3$.

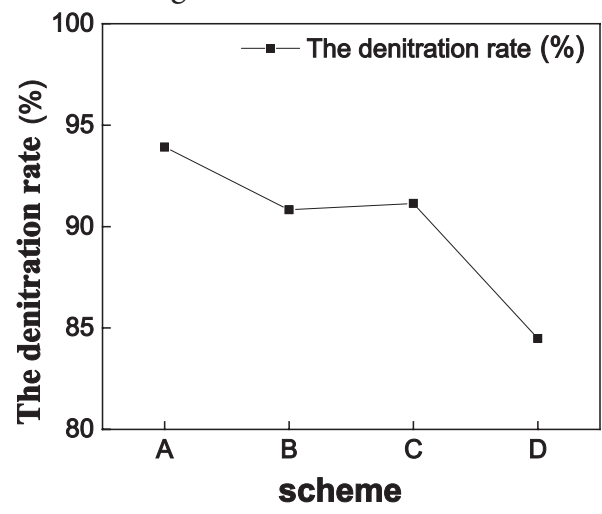

Fig. 7. Denitrification of different schemes 
The denitrification rate of the four diesel engine flue gas flow schemes is different. Programme A has the largest denitrification rate of $93.92 \%$, at this time, the denitrification efficiency of the SCR reactor is optimal. Plan D denitrification rate is the lowest, at $84.48 \%$, this is because the plan $\mathrm{D}$ maximum flow, high temperature, a part of $\mathrm{NH}_{3}$ easy to oxidation, lead to part of $\mathrm{NO}_{\mathrm{x}}$ is not oxidation, so the denitrification rate is low. Although the catalytic efficiency of programme $\mathrm{D}$ is less than that of the other three schemes, it is more than $80 \%$ and meets the emission requirements.

\section{CONCLUSIONS}

In this paper, $\mathrm{NO}_{\mathrm{x}}$ is used to determine the amount of $\mathrm{NO}_{\mathrm{x}}$ in flue gas under stable condition of diesel engine by $\mathrm{NO}_{x}$ sensor to calculate the amount of urea solution that needs to be sprayed. And then we build the appropriate geometric model of the injection grid, the effect of spray atomization flow field distribution, ammonia uniformity and urea droplet distribution on atomization results was simulated. Set up the test bench to observe the injection status of the injection grate, by testing the correctness of the scheme, the experimental data are processed and the following conclusions are drawn.

In the simulation, we found that the spray atomization effect of the $4 \times 6$ sprayed ammonia grille designed in this paper is better. Before starting the experiment, ammonia injection grid carried out the external experiment of the system, and the spray atomization effect was better, which met the requirements of the system. To calculate the denitrification rate of the SCR system experiment, the denitrification rate of four diesel engine flue gas flow schemes is different, but it is more than $80 \%$ and meets the emission requirements.

\section{ACKNOWLEDGEMENTS}

This project is partially supported by Jiangsu University of Science and Technology.

\section{REFERENCES}

1. Baik J H, Yim S D, Nam I S, et al., Control of $\mathrm{NO}_{x}$ emissions from diesel engine by selective catalytic reduction (SCR) with urea [J]. Topics in Catalysis, 2004, 30-31(1-4): 37-41.

2. Lei Z, Wen C, Chen B., Optimization of internals for Selective Catalytic Reduction (SCR) for NO removal [J]. Environmental Science \& Technology, 2011, 45(8): 3437-3444.

3. Chen, Ming, and S. Williams. Modelling and Optimization of SCR-Exhaust Aftertreatment Systems. SAE 2005 World Congress \& Exhibition, 2005.

4. Weltens, Herman, et al., Optimisation of Catalytic Converter Gas Flow Distribution by CFD Prediction. International Congress \& Exposition, 1993.
5. Ho Jeong Chae, 500Tac Choo, Hoon Choe, et al., Direct use of Knetic parameters for modeling and simulation of a selective catalytic reduction Process [J] Ind. Eng. Chem. Res. 2000 39(5): 1159-1170.

6. Tronconi E, Beretta A, Elmi A S, et al., A complete model of scr monolith reactors for the analysis of interacting $\mathrm{NO}_{x}$, reduction and $\mathrm{SO}_{2}$, oxidation reactions [J]. Chemical Engineering Science, 1994, 49(24): 4277-4287.

7. Upadhyay D, Nieuwstadt M V. Model Based Analysis and Control Design of a Urea-SCR deNO Aftertreatment System [J]. Journal of Dynamic Systems Measurement \& Control, 2006, 128(3): 737-741.

8. Bhattacharjee S, Haworth D C, Moores R. CFD modeling of processes upstream of the catalyst for urea SCR NO reduction systems in heavy-duty diesel applications [J]. Sae Technical Papers, 2011.

9. Adams B, Cremer M, Valentine J, et al., Use of CFD Modeling for Design of NOx Reduction Systems in Utility Boilers [C]. International Joint Power Generation Conference. 2002: 695-702.

10. Naqvi Mughis Meyer Chris. Gas-Gas Mixing as Applied to SCR's [C].NETL conference Pittsburgh Pennsylvania 2003: $1-30$.

11. Enrico Tronconi, Andrea Cavanna, Carlo OrseIligo, Pio Forzani, Transient Kinetics of S02 Oxidation Over SCR-DeNOx Monolith Cataysts. Industrial \& Engineering Chemistry Research, 1999, 38(7): 2593-2598.

12. Tao Qiu,Xuchu Li,Hong Liang,Xinghua Liu, Yan Lei. A method for estimating the temperature downstream of the SCR (selective catalytic reduction) catalyst in diesel engines [J]. Energy,2014,68.

13. Ossi Tapani Kaario,Ville Vuorinen,Lei Zhu,Martti Larmi, Ronghou Liu. Mixing and evaporation analysis of a highpressure SCR system using a hybrid LES-RANS approach [J]. Energy, 2016.

14. Amsden A A, Orourke P J, Butler T D. KIVA-2: A computer program for chemically reactive flows with sprays [J]. Nasa Sti/recon Technical Report N, 1989, 89.

15. Yim S D, Kim S J, And J H B, et al., Decomposition of Urea into NH3 for the SCR Process [J]. Industrial \& Engineering Chemistry Research, 2004, 43(16): 4856-4863.

16. Weili Zhang. Study on the urea storage and injection unit of the ship SCR system. Dalian Maritime University. 2012: 1-62. 


\section{CONTACT WITH THE AUTHOR}

Jun Du, Associate professor. e-mail:dujun9988@163.com tel: +86-15996805827

Jiangsu University of Science and Technology 23-102 Mengxi Road 6

Zhenjiang City Jiangsu Province

212003

China 